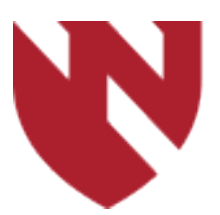

\title{
Transradial vs. Transfemoral Access for Percutaneous Coronary Intervention in STEMI: Meta-Analysis of Randomized Controlled Trials
}

\author{
Aravdeep Jhand \\ University of Nebraska Medical Center \\ Varunsiri Atti \\ Michigan State University \\ Rahul Dhwan \\ University of Nebraska Medical Center \\ Mohit Turagam \\ Icahn School of Medicine at Mount Sinai \\ Mamas Mamas \\ Keele University
}

Tell us how you used this information in this short survey.

Perforexthpage fordafflitianalorkthat:Sttps://digitalcommons.unmc.edu/gmerj

Part of the Higher Education Commons, and the Medicine and Health Sciences Commons

\section{Recommended Citation}

Jhand, A., Atti, V., Dhwan, R., Turagam, M., Mamas, M., Kataa, N., Chatzizisis, Y., Kirtane, A., Bhatt, D., , Velagapudi, P. Transradial vs. Transfemoral Access for Percutaneous Coronary Intervention in STEMl: Meta-Analysis of Randomized Controlled Trials. Graduate Medical Education Research Journal. 2020 Sep 29; 2(1).

https://digitalcommons.unmc.edu/gmerj/vol2/iss1/59

This Conference Proceeding is brought to you for free and open access by DigitalCommons@UNMC. It has been accepted for inclusion in Graduate Medical Education Research Journal by an authorized editor of DigitalCommons@UNMC.For more information, please contact digitalcommons@unmc.edu. 


\section{Transradial vs. Transfemoral Access for Percutaneous Coronary Intervention in STEMI: Meta-Analysis of Randomized Controlled Trials}

\section{Creative Commons License}

\section{(c) (i) $\Theta($}

This work is licensed under a Creative Commons Attribution-Noncommercial-No Derivative Works 4.0 License.

\section{Authors}

Aravdeep Jhand, Varunsiri Atti, Rahul Dhwan, Mohit Turagam, Mamas Mamas, Natraj Kataa, Yiannis Chatzizisis, Ajay Kirtane, Deepak Bhatt, and Poonam Velagapudi 
were all cause mortality, MI, stroke and repeat revascularization. Odds ratios (OR) and $95 \%$ Confidence Intervals (CI) were calculated. The analysis was performed using DerSimonian and Laird random effect model.

Results: In total, six studies (four observational and two randomized controlled trials) met our inclusion criteria with a total of 2198 patients (CABG: 1050, PCI: 1148). Patients undergoing $\mathrm{CABG}$ had a higher incidence of multivessel disease $(74.7 \%$ vs $65.7 \%, \mathrm{p}=0.01)$ At a mean follow-up of $3.4+/-1.1$ years, the incidence of MACCE was significantly lower in $\mathrm{CABG}$ group as compared to $\mathrm{PCI}$ group $(\mathrm{OR}=0.70,95 \% \mathrm{CI}=$ $0.57-0.87 ; \mathrm{p}=0.001$ ) (Figure 1). The odds of $\mathrm{MI}$ or repeat revascularization were lower with $\mathrm{CABG}$, whereas the odds of stroke were higher; no statistically significant difference was seen in all-cause mortality.
Conclusion: Our analysis shows that $\mathrm{CABG}$ is associated with better long-term outcomes as compared to PCI in LMCAD patients with CKD.

https://doi.org/10.32873/unmc.dc.gmerj.2.1.056

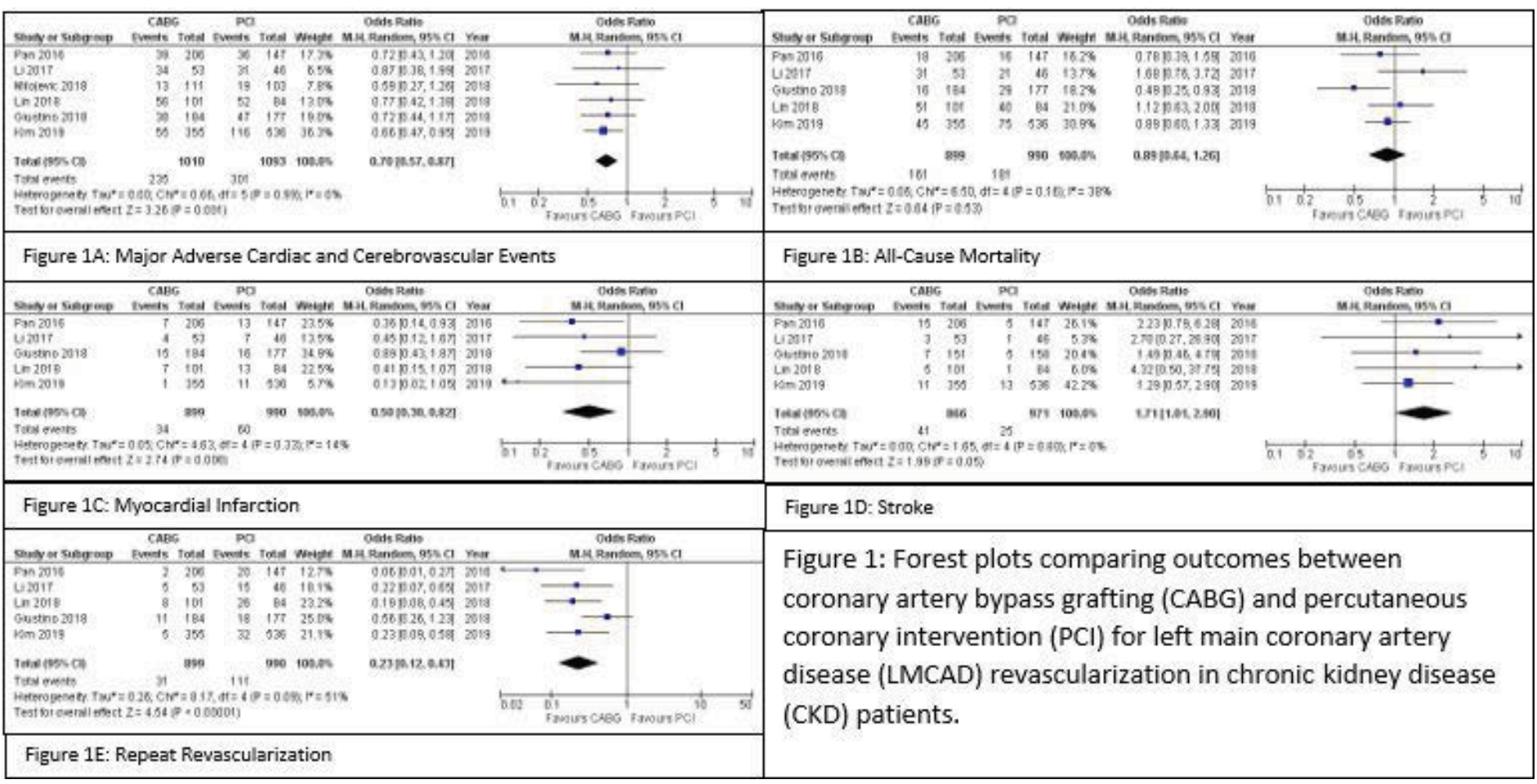

Figure 1. Forest plots comparing outcomes between $C A B G$ and PCI for $L M C A D$ revascularization in CKD patients.

\section{Transradial vs. Transfemoral Access for Percutaneous Coronary Intervention in STEMI: Meta-Analysis of Randomized Controlled Trials}

Aravdeep Jhand ${ }^{1}$, Varunsiri Atti ${ }^{2}$, Rahul Dhwan ${ }^{1}$, Mohit Turagam³ ${ }^{3}$, Mamas Mamas ${ }^{4}$, Natraj Kataa ${ }^{1}$, Yiannis Chatzizisis ${ }^{1}$, Ajay Kirtane ${ }^{5}$, Deepak Bhatt ${ }^{6}$, Poonam Velagapudi'

${ }^{1}$ University of Nebraska Medical Center, Department of Internal Medicine, Division of Cardiovascular Disease

${ }^{2}$ Michigan State University, Department of Internal Medicine

${ }^{3}$ Icahn School of Medicine at Mount Sinai, Department of Internal Medicine, Division of Cardiac Electrophysiology

${ }^{4}$ Keele University, Department of Internal Medicine, Division of Cardiovascular Disease

${ }^{5}$ Columbia University, Department of Internal Medicine, Division of Cardiovascular Disease

${ }^{6}$ Brigham and Women Hospital, Department of Internal Medicine, Division of Cardiovascular Disease

Mentor: Poonam Velagapudi

Program: Internal Medicine, Division of Cardiovascular Disease

Type: Review/Meta-analysis

Background: Transradial access (TRA) is now increasingly used for percutaneous coronary intervention (PCI) in ST Elevation Myocardial Infarction (STEMI) vis-à-vis Transfemoral access (TFA). We conducted a meta-analysis of randomized controlled trials to evaluate the long term efficacy and safety of the two approaches in STEMI-PCI.

Methods: PubMed, Cochrane, Embase databases and major national conference proceedings were systematically searched for clinical trials comparing TRA and TFA in patients undergoing PCI for STEMI. Efficacy outcomes studied were all-cause mortality, major adverse cardiovascular events (MACE), myocardial infarction (MI) and stroke. Safety outcomes included major bleeding and vascular complications. Odds ratios (OR) and $95 \%$ Confidence Intervals (CI) were calculated. The analysis was performed using DerSimonian and Laird random effects model.

Results: In total, 17 trials met our inclusion criteria with a total of 12018 patients (TRA: 5958 and TFA: 6060). There was no statistically significant difference in procedure duration and fluoroscopy time among the two groups, however, hospital length of stay was significantly lower in the TRA group (Figure 
1). At a mean follow-up of $2.3+/-2.8$ months, rates of all-cause mortality (OR: $0.70,95 \% \mathrm{CI}$ $=0.56-0.88)$, major bleeding (OR: $0.58,95 \%$ $\mathrm{CI}=0.44-0.76)$ and vascular complications (OR: $0.38,95 \% \mathrm{CI}=0.28-0.51$ ) were lower in TRA as compared to TFA while there was no difference in rates of MACE, MI and stroke between groups.

Conclusion: Our analysis shows that TRA is associated with better long-term survival as compared to TFA along with lower rates of major bleeding and vascular complications in STEMI patients undergoing PCI.

https://doi.org/10.32873/unmc.dc.gmerj.2.1.057

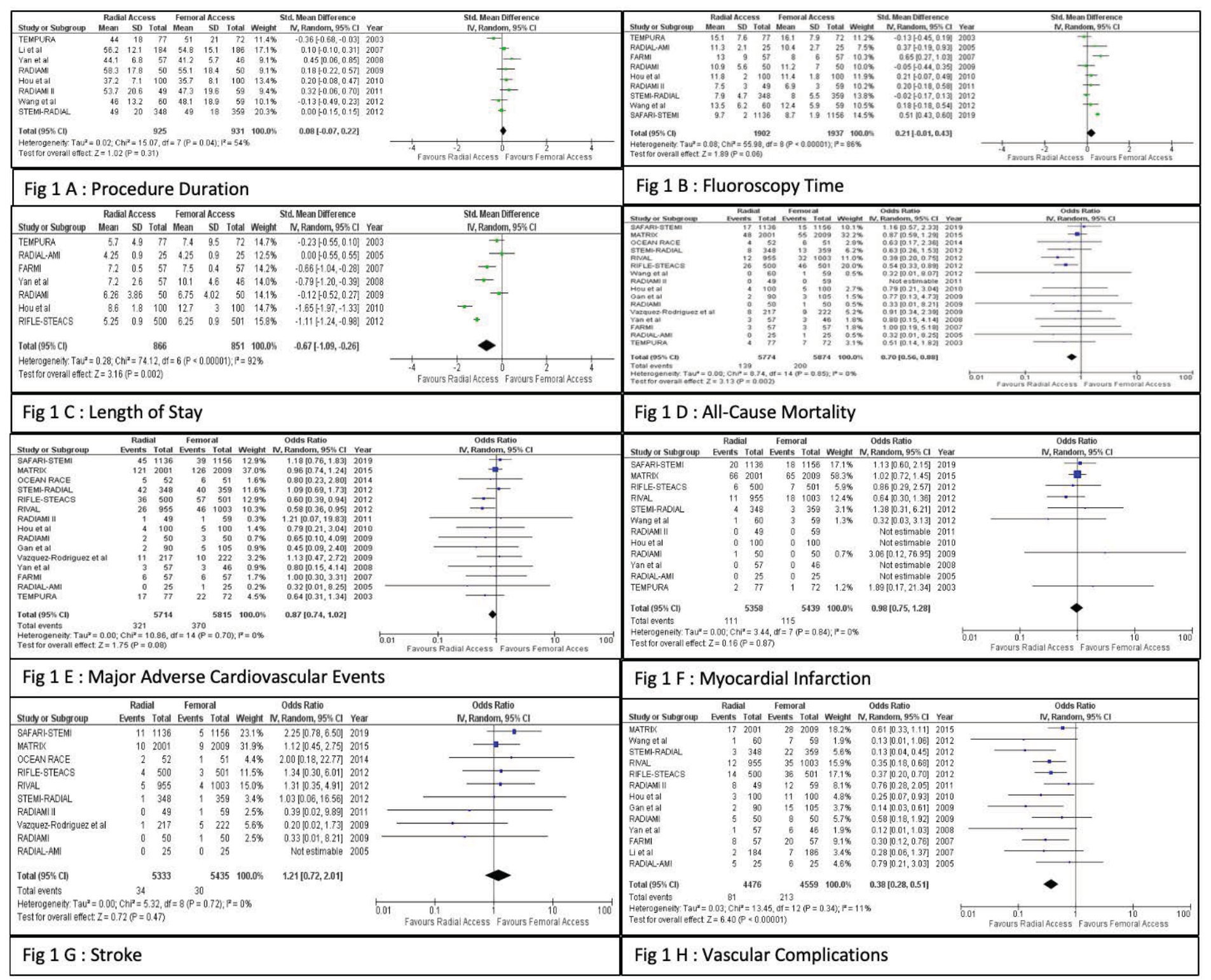

Figure 1. Forest plots showing outcomes with transradial and transfemoral approaches in STEMI.

\section{Virchow's Triad in Action}

Adam Karevoll', Trek Langenhan'1, Allison Ashford ${ }^{1}$

${ }^{1}$ University of Nebraska Medical Center, Department of Internal Medicine

Mentor: Mark Mailliard

Program: Internal Medicine

Type: Case Report

Background: A 21 year-old man presented with a two-day history of left leg pain and swelling following recent admission for nontraumatic splenic rupture due to presumed infectious mononucleosis. He had swelling, tenderness and erythema of the left lower extremity, primarily surrounding the calf. Doppler ultrasound revealed non-occlusive deep vein thrombosis (DTV) of the left proximal femoral vein and he was started on apixaban for anticoagulation. Laboratory workup for clotting disorder revealed heterozygous Factor V Leiden mutation. One week later his leg pain and swelling worsened. Repeat Doppler revealed extensive progression of the DVT despite appropriate 